\title{
Afetividade nas práticas pedagógicas
}

\author{
Sérgio Antônio da Silva Leite \\ Universidade Estadual de Campinas - Campinas, SP, Brasil
}

\begin{abstract}
Resumo
$\mathrm{O}$ presente texto analisa o papel da afetividade nas práticas pedagógicas desenvolvidas por professores em sala de aula. Tendo como suporte as ideias de Vygotsky e Wallon, assume-se, como pressuposto, que as relações que se estabelecem entre o sujeito, o objeto de conhecimento e o agente mediador também são profundamente marcadas pela dimensão afetiva, uma vez que produzem impactos subjetivos no sujeito. Tais impactos podem gerar movimentos de aproximação ou de distanciamento entre o sujeito e o referido objeto de conhecimento; essas relações podem ser estudadas na situação de sala de aula. Neste sentido, pretende-se identificar e analisar algumas decisões pedagógicas planejadas e desenvolvidas por professores e seus impactos afetivos nas relações que se estabelecem entre o aluno e os conteúdos escolares. Dados acumulados de pesquisas permitem identificar que as decisões que promovem o sucesso na aprendizagem aumentam as chances de se estabelecer uma relação afetiva positiva entre o aluno e os conteúdos escolares - aqui designada como uma relação de aproximação afetiva.
\end{abstract}

Palavras-chave: Aprendizagem, Afetividade, Práticas pedagógicas, Mediação do professor.

\section{Affection in teaching practices}

\begin{abstract}
This paper discusses the role of affectivity in pedagogical practices developed by teachers in the classroom. With the theoretical support of Vygotsky and Wallon ideas, it is assumed that the relations established between the subject, the object of knowledge and the mediator are also deeply influenced by the affective dimension, since they produce impacts on subjective subject. Such impacts can generate approximation or separation movements between the subject and the object of such knowledge; these relations can be observed in the classroom situation. We aim to identify and analyze some pedagogical decisions planned and developed by teachers and their impacts on affective relations that are established between the student and the school contents. Research data permit to identify the teacher decisions that promote success in learning, increasing the chances of establishing a positive affective relation between the student and the school contents - here designated as a relation of affective approach.
\end{abstract}

Keywords: Learning, Affection, Teaching practices, Teacher mediation.

\section{Afectividad en las prácticas pedagógicas}

\section{Resumen}

El presente texto analiza el papel de la afectividad en las prácticas pedagógicas desarrolladas por profesores en el salón de clase. Con el respaldo de las ideas de Vygotsky y Wallon, se supone que las relaciones que se establecen entre el sujeto, el objeto de conocimiento y el mediador también están profundamente influenciadas por la dimensión afectiva, ya que producen impactos en la subjetividad del sujeto. Estos impactos pueden generar movimientos de acercamiento o de alejamiento entre el sujeto y el objeto de conocimiento; estas relaciones pueden ser estudiadas en el salón de clase. Nuestro objetivo es identificar y analizar algunas decisiones pedagógicas planificadas y desarrolladas

Endereço para correspondência: Rua Cayowáa, 1553, apt. 10. Bairro Sumaré, São Paulo/SP, Brasil. CEP: 01258-011. E-mail: sasleite@uol.com.br. Telefones: +55 11 3673-0759 / +55 11 9932-4673.

Artigo aceito durante a gestão do editor Gerson Tomanari. 
por los docentes y su impacto en la relación afectiva que se establece entre el alumno y los contenidos escolares. Datos acumulados de investigación permiten identificar las decisiones que promueven el éxito en el aprendizaje y aumentan las posibilidades de establecer una relación afectiva positiva entre el estudiante y el contenido de la escuela - designada aquí como una relación de acercamiento afectivo.

Palabras clave: Aprendizaje, Afectividad, Prácticas pedagógicas, Mediación del profesor.

\section{Introdução: caracterização do problema}

A afetividade e suas implicações com o ensino tem sido um tema crescentemente abordado no ambiente acadêmico, nas últimas duas décadas. Obviamente, as emoções e os afetos sempre foram objetos das grandes teorias psicológicas, porém muito mais como preocupação teórica do que como objeto de produção de pesquisas científicas.

Como ilustração, em nosso meio, nos anos 70 do século passado, Engelman (1978) realizou uma ampla revisão das variações semânticas das palavras e conceitos relacionados com as emoções, sentimentos, estados de ânimo, afetos e estados afetivos. Seus estudos mostram que os autores, até então, embora reconhecessem a necessidade de estabelecer distinções entre os diversos conceitos, na realidade, refletiam grandes discordâncias sobre tais diferenciações.

No entanto, podemos reafirmar que, em nosso meio, nas últimas duas décadas, observase que o tema da afetividade passou a ter uma presença crescente na agenda de pesquisa de vários estudiosos da área educacional, com destaque para autores vinculados à Psicologia (Almeida, 1997, 1999; Dantas, 1992; Mahoney, 1993; Oliveira, 1992; Pinheiro, 1995; Arantes \& Aquino, 2003; Vasconcelos, 2004; Leite, 2006; Ribeiro \& Jutras, 2006; Franco, 2009; Amado, Freire, Carvalho \& André, 2009; Ribeiro, 2010).

Neste texto, pretende-se discutir a dimensão afetiva nas práticas pedagógicas desenvolvidas em sala de aula. Assume-se que a mediação pedagógica também é de natureza afetiva e, dependendo da forma como é desenvolvida, produz impactos afetivos, positivos ou negativos, na relação que se estabelece entre os alunos e os diversos conteúdos escolares desenvolvidos. Tais impactos são caracterizados por movimentos afetivos de aproximação ou de afastamento entre o sujeito/aluno e os objetos/conteúdos escolares.

Pretende-se, também, discutir algumas decisões pedagógicas que os professores assumem quando planejam ou desenvolvem seus cursos, a partir de dados acumulados por diversas pesquisas coordenadas pelo autor, indicando os possíveis impactos afetivos nos alunos.

\section{Razão-emoção: concepções dualistas $\mathrm{x}$ concepções monistas}

Um dos desafios teóricos que se colocaram, quando começamos a estudar a dimensão afetiva, foi entender as razões pelas quais este conceito permaneceu historicamente periférico nas relações de ensino e aprendizagem, embora sua importância não tenha sido negada pelas tradicionais teorias psicológicas. Julgamos que este fato está, ao menos parcialmente, vinculado ao predomínio secular da chamada concepção dualista, segundo a qual o homem é entendido como um ser cindido entre razão e emoção, cujas raízes vêm desde a Antiguidade, fortalecendo-se com a tradicional dualidade cartesiana entre corpo e alma, na Modernidade: os afetos, como parte da dimensão anímica, não poderiam ser objetos de estudos científicos.

Entender que o homem é um ser cindido entre razão e emoção é assumir que o homem é um ser que ora pensa, ora sente, não havendo vínculos ou relações determinantes entre essas duas dimensões. Além disso, enfrenta-se o problema típico de todo o pensamento dualista: supõe-se que o homem apresenta uma dimensão que não é passível de uma abordagem científica; o que significa assumir, como pressuposto, que a ciência nunca poderá explicar o fenômeno humano por completo.

Além disso, no caso da dualidade razão $\mathrm{x}$ emoção, durante séculos o pensamento dominante, além de assumir o dualismo, elegeu a razão como a dimensão superior, que melhor caracteriza o homem, chegando a situar a 
emoção como o lado sombrio e nebuloso da natureza humana, responsável por grande parte de suas mazelas: assim, seria função da razão o controle/domínio sobre a emoção, ou seja, só assim o homem não correria o risco de perder a razão.

O domínio hierárquico da razão sobre a emoção é observado nos diferentes períodos históricos: na Antiguidade, pela oposição entre conhecimento inteligível (passível de uma abordagem objetiva) e conhecimento sensível (não científico), sendo os sentimentos considerados não passíveis de um conhecimento objetivo pelo seu grau de subjetividade. Na Idade Média, pelo conflito entre razão e fé, com o predomínio desta sobre aquela. $\mathrm{Na}$ Modernidade, pelo dualismo cartesiano, embora tenha ocorrido uma crescente valorização do indivíduo como ser pensante, portador de uma consciência individual e de liberdade. $\mathrm{Na}$ sequência histórica, entendemos que o ápice do predomínio racionalista ocorreu no final do século XIX, com o Positivismo, de Augusto Comte $^{1}$, ratificando que o conhecimento só é possível através da razão ${ }^{2}$.

É inegável a influência secular da concepção dualista nas práticas das instituições educacionais: herdamos uma concepção segundo a qual o trabalho educacional envolve e deve ser dirigido, essencialmente, para o desenvolvimento dos aspectos cognitivos, centrados na razão, sendo que a afetividade não deve estar envolvida nesse processo. Neste sentido, os currículos e programas desenvolvidos, nos diferentes momentos da nossa política educacional, centraram-se no desenvolvimento da dimensão racionalcognitiva, através do trabalho pedagógico em sala de aula, em detrimento da dimensão afetiva.

Com o desenvolvimento da ciência e da pesquisa, em quase todas as áreas do conhecimento, principalmente a partir do século XVIII, criam-se as condições para a construção de um modelo teórico mais adequado; esse modelo nos possibilitou entender que razão e emoção são indissociáveis, dois lados de uma mesma

\footnotetext{
1 1789-1857.

${ }^{2}$ Análise dessas questões podem ser encontradas em Marcondes (2000); Bosch (1998); Figueiredo (1992); Giles (1993).
}

moeda, mantendo entre si íntimas relações. Tais questões criaram as condições para $\mathbf{O}$ surgimento da chamada concepção monista sobre a constituição humana.

As concepções dualistas, historicamente, têm sido contestadas. Somente no século passado, com o advento de teorias filosóficas, sociológicas e psicológicas centradas nos determinantes culturais, históricos e sociais do processo de constituição humana, criaram-se as bases para uma nova compreensão sobre o próprio homem e, no nosso caso, das relações entre razão e emoção. O pensamento humano caminhou, assim, na direção de uma concepção monista, em que afetividade e cognição passam a ser interpretadas como dimensões indissociáveis e parte do mesmo processo, não sendo mais possível analisá-los separadamente.

Um dos filósofos cujo pensamento desempenhou um papel histórico fundamental no processo de superação da concepção dualista foi Baruch de Espinosa ${ }^{3}$ (Spinoza, 2009; Chauí, 2005; Damásio, 2003), que nos chama a atenção não só pelo conteúdo das suas ideias, mas, principalmente, pelo momento em que foram elaboradas e divulgadas - em pleno século XVII.

Espinosa defendia que o corpo e mente são atributos de uma substância única; assumiu que corpo e alma seguem as mesmas leis, rompendo, assim, com a hierarquia secular que situava a alma como instância superior ao corpo.

Pode-se, assim, ilustrar a radical mudança relacionada à concepção humana pelo contraste entre duas máximas, elaboradas num intervalo de três séculos e meio: de um lado, a máxima cartesiana $^{4}$ penso, logo existo ${ }^{5}$, em que a razão/pensamento é interpretada como motivo da existência; de outros lado, a máxima recente do neurofisiólogo Antonio Damásio existo e sinto, logo penso (Damásio, 2001), propondo uma clara inversão do domínio secular da razão sobre a emoção, anunciando que esta é a base para a constituição da estrutura cognitiva do ser humano - posição semelhante também assumida por Wallon.

\footnotetext{
${ }^{3} 1632-1677$.

${ }^{4}$ Descartes, 1596-1650.

5 A obra de Descartes "Discurso do Método" foi publicada em 1637.
} 


\section{O Grupo do Afeto}

Com relação ao nosso trabalho acadêmico, desde o final dos anos 1990, nos envolvemos com a dimensão afetiva na mediação pedagógica em sala de aula. Nesse período, conseguimos reunir um grupo de orientandos dos diversos níveis - doutorado, mestrado e iniciação científica - carinhosamente chamado de Grupo do Afeto $^{6}$, que vem desenvolvendo diversos estudos e pesquisas sobre o tema.

Deve-se destacar que o nosso envolvimento com a afetividade se deu a partir dos estudos que já vínhamos desenvolvendo sobre Alfabetização Escolar e Letramento. Especificamente, com o direcionamento do foco de nossa atenção para o problema do processo de constituição do sujeito como leitor, levando-nos ao aprofundamento teórico sobre o tema e a propostas de pesquisas que nos possibilitaram um melhor conhecimento do fenômeno em questão.

Os estudos desenvolvidos no Grupo do Afeto centraram-se nas chamadas abordagens qualitativas (Ludke \& André, 1986; Bogdan \& Biklen, 1994). Segundo esses autores, a investigação qualitativa é um termo genérico que agrupa diversas estratégias de investigação que compartilham as características comuns. Os dados qualitativos, ainda segundo eles, devem ser ricos em pormenores descritivos, visando investigar os fenômenos em toda a sua complexidade e no ambiente natural. Neste sentido, as estratégias para coleta de dados mais representativas da pesquisa qualitativa são a observação participante e a entrevista em profundidade, frequentemente utilizadas nas pesquisas etnográficas e nos estudos de caso.

No presente caso, um dos fatores que, certamente, muito facilitaram nosso envolvimento com a pesquisa foi a aproximação com os procedimentos de coleta de dados, denominados de entrevistas recorrentes e autoscopia (Sadalla \& Larocca, 2004; Leite \& Colombo, 2006).

A Autoscopia é um procedimento de coleta de dados conhecido como confrontação de si na tela: são realizadas sessões de gravação do comportamento do sujeito (ex: relações em sala de aula) e, após edição da fita, o sujeito é colocado em uma situação para observar o

\footnotetext{
${ }^{6} \mathrm{O}$ Grupo do Afeto é parte integrante do grupo de pesquisa ALLE- Alfabetização Leitura Escrita, da Faculdade de Educação da Unicamp.
}

material gravado, sendo estimulado verbalmente pelo pesquisador para emitir comentários em função dos objetivos da pesquisa. Segundo Leite \& Colombo (2006),

os dados primários são os relatos verbais emitidos pelo sujeito na situação de observação de suas imagens na tela da TV, durante ou após a transmissão, os quais, por sua vez, são também gravados para posterior análise. ( p. 119)

O produto dessa análise, geralmente, são núcleos temáticos que, no seu conjunto, correspondem aos resultados da pesquisa realizada.

Com relação ao procedimento de autoscopia, o primeiro trabalho no Grupo do Afeto foi o de Tassoni (2000), que identificou e analisou a dimensão afetiva, nas relações professor-aluno, em classes de pré-escola, com crianças de seis anos de idade.

Entrevistas recorrentes, por sua vez, é um procedimento de coleta e análise de dados inspirado nos trabalhos pioneiros de Tunes (1981), Simão (1982) e Goyos (1986). Mais recentemente sob nossa orientação acadêmica, podemos citar os trabalhos de Zanelli (1992), Guanais (1995), Larocca (1999) e Grotta (2000). Trata-se de uma estratégia que implica um intenso processo interativo entre $o$ pesquisador e o(s) sujeito(s), sendo que este participa da fase inicial do processo de análise de dados, que ocorre simultaneamente ao processo de coleta dos dados.

Em termos gerais, o procedimento pode ser assim resumido: a) a escolha dos sujeitos que serão entrevistados é intencional, devendo estar claramente especificados o seu perfil, bem como as estratégias para a escolha; b) na primeira entrevista, que geralmente é individual, após recolocar os objetivos da pesquisa, o pesquisador apresenta uma questão básica, relacionada com o eixo central dos objetivos, solicitando que o sujeito verbalize livremente. Os relatos são gravados, em vídeo ou áudio, mediante consentimento do sujeito; c) na sequência, a fita da primeira entrevista é transcrita e o pesquisador inicia a primeira etapa do processo de análise dos dados: organizar os conteúdos em núcleos temáticos, que deverão ser apresentados numa matriz, contendo o título de cada núcleo, suas respectivas definições e o rol dos recortes dos fragmentos de fala do sujeito que deram origem 
aos núcleos; d) com esse material pronto, o pesquisador solicita uma segunda entrevista com o sujeito, onde apresenta, inicialmente, as matrizes contendo os núcleos temáticos e solicita ao sujeito que complemente, altere, amplie ou mantenha os núcleos elaborados. Além disso, o pesquisador deverá apresentar as dúvidas específicas surgidas, bem como outras questões elaboradas; e) os dados da segunda entrevista também deverão ser transcritos e incluídos nos núcleos temáticos já existentes, o que pode ampliar os núcleos temáticos, a partir da matriz inicial; f) outras entrevistas poderão ocorrer seguindo o mesmo procedimento acima descrito. Essa etapa de coleta e análise inicial de dados é encerrada quando sujeito e pesquisador concordarem que o assunto foi adequadamente abordado, não havendo mais novas considerações; g) após as entrevistas com todos os sujeitos, inicia-se a segunda etapa de análise, agora sob a responsabilidade somente do pesquisador, com o cotejamento de todas as matrizes individuais. A meta é a construção de uma matriz final, que deverá abranger o conjunto de núcleos temáticos com todos os dados considerados relevantes, verbalizados pelos sujeitos, sobre os objetivos da pesquisa. Esses serão, portanto, os resultados da pesquisa: o conjunto dos núcleos temáticos, com seus títulos, definições e conteúdos verbais, os quais deverão ser, posteriormente, objetos de discussão e interpretação, à luz da abordagem teórica assumida.

Um dos primeiros trabalhos que orientamos, utilizando o procedimento de entrevistas recorrentes, foi o de Grotta (2000), que analisou o processo de constituição de leitores de quatro sujeitos adultos.

A partir desses projetos iniciais, as pesquisas foram desenvolvidas, tendo como objeto as relações que ocorrem em sala de aula. Especificamente, a maioria das pesquisas estudou as mediações pedagógicas planejadas e desenvolvidas pelos professores. O livro que organizamos (Leite, 2006) representou um marco importante nesse processo ocorrido no Grupo do Afeto: foi planejado e escrito visando, principalmente, aos educadores que atuam nas redes de ensino e demais professores e estudantes, que tenham interesse pelo tema.

Assim, durante esse período, é possível identificar três grandes eixos que nortearam os trabalhos desenvolvidos no Grupo do Afeto: a afetividade nas relações interpessoais professor-aluno-aluno; o processo de constituição do sujeito como leitor; a afetividade nas práticas pedagógicas, planejadas e desenvolvidas pelos professores em sala de aula. É sobre este último eixo que se relaciona o presente texto.

Após os primeiros trabalhos de pesquisa sobre o tema, focando principalmente as relações interpessoais em sala de aula, logo percebemos que a dimensão afetiva extrapola os limites das relações epidérmicas e contatos face a face. Os estudos que orientamos e acompanhamos sobre o professor inesquecível (Falcin, 2003; Tagliaferro, 2003) apontaram, de forma clara, que todas as decisões planejadas e desenvolvidas pelos professores produzem fortes impactos afetivos nos alunos, mesmo quando os docentes não estão fisicamente presentes na situação, como ocorre nas relações face a face. Isto nos levou a ampliar o nosso olhar para as práticas/mediações pedagógicas, envolvidas especificamente com as condições de ensino, tentando identificar e analisar a repercussões que as mesmas produzem nas relações que se estabelecem entre os alunos/sujeitos e os respectivos conteúdos escolares/objetos abordados em sala de aula. Assim, o foco do nosso olhar sobre a dimensão afetiva passou a ser, especificamente, os processos de ensino e de aprendizagem que ocorrem na sala de aula.

\section{Bases teóricas}

Este é um tema sobre o qual é fundamental a construção de um modelo teórico adequado, que possibilite uma compreensão que ultrapasse o olhar tradicional ou o senso comum sobre a relação razão x emoção, como já foi discutido. Um modelo teórico que nos ajude a entender que o Homem é um ser único; que o dualismo é uma leitura artificial da constituição humana, produzido pelo próprio Homem em função de determinadas condições históricas, políticas e sociais; que o Homem é um ser que pensa e sente simultaneamente, sendo que a emoção está sempre presente na relação do Homem com a cultura; que, portanto, razão e emoção são indissociáveis, o que aponta para uma concepção holística/monista_sobre a constituição humana. Enfim, este é um tema que exige estudo e o exercício da reflexão sobre o mesmo, uma vez que essas questões frequentemente esbarram e colidem com velhas concepções ideológicas, de natureza liberal, muitas delas ainda fortemente 
presentes na própria constituição de nossa subjetividade.

O conjunto de pressupostos teóricos, presente desde o início do trabalho com o Grupo do Afeto, foi sendo gradualmente solidificado, à medida que novos dados e relações iam sendo analisados a cada pesquisa desenvolvida. Tais pressupostos foram estabelecidos a partir de dois grandes teóricos da Psicologia contemporânea: L. S. Vygotsky e H. Wallon.

Portanto, no campo da teoria psicológica, buscamos respaldo, para ancorar as pesquisas do Grupo do Afeto, em autores que apresentam, em comum, teorias com pressupostos centrados na concepção materialista dialética, segundo a qual o processo de desenvolvimento humano e, portanto, as funções superiores que caracterizam o homem devem ser explicados pelas relações que o homem mantém com a sua cultura, no seu ambiente social. Para esses autores, o objetivo da teoria psicológica é explicar os mecanismos pelos quais os processos naturais/filogenéticos, presentes no recém-nascido, se mesclam com os processos culturais e sociais para produzir as funções complexas que caracterizam o homem maduro.

Wallon (1968, 1971, 1978) desenvolveu uma teoria sobre o processo de desenvolvimento humano centrado no processo de relação entre quatro grandes núcleos funcionais, determinantes do processo: a afetividade, a cognição, o movimento e a pessoa. Para o autor, o processo de desenvolvimento, que ocorre através da contínua interação entre esses núcleos, só pode ser explicada pela relação dialética entre os processos biológicos/orgânicos e o ambiente social - ou seja, o biológico e o social são indissociáveis, estando dialeticamente sempre relacionados.

Para Wallon (1968), as emoções são manifestações de estados subjetivos, mas com componentes orgânicos (contrações musculares, viscerais, etc.). Assim, na teoria walloniana, a emoção é o primeiro e mais forte vínculo que se estabelece entre o sujeito e as pessoas do ambiente, constituindo as manifestações iniciais de estados subjetivos, com componentes orgânicos. Apresenta três propriedades: a) contagiosidade - a capacidade de contaminar o outro; b) plasticidade - a capacidade de refletir sobre o corpo os seus sinais; c) regressividade _ a capacidade de regredir as atividades ao raciocínio. Para o autor (Wallon, 1971), caberá às manifestações emocionais, através do seu poder de contágio, possibilitar ao recém-nascido sensibilizar as pessoas do ambiente para satisfazer suas necessidades e desejos.

A afetividade, por sua vez, envolve uma gama maior de manifestações, englobando as emoções (de origem biológica) e os sentimentos (de origem psicológica). Neste sentido, é um processo mais amplo, que envolve a emoção, o sentimento e a paixão. Segundo Mahoney (2004),

as emoções são identificadas pelo seu lado orgânico, empírico e de curta duração; os sentimentos, mais pelo componente representacional e de maior duração [...] A paixão é encoberta, mais duradoura, mais intensa, mais focada e com mais autocontrole sobre o comportamento. (p. 17-18)

Assim, a afetividade é um conceito mais amplo, constituindo-se mais tarde no processo de desenvolvimento humano, envolvendo vivências e formas de expressão mais complexas, desenvolvendo-se com a apropriação, pelo indivíduo, dos processos simbólicos da cultura, que vão possibilitar sua representação. É um conceito que "além de envolver um componente orgânico, corporal, motor e plástico, que é a emoção, apresenta também um componente cognitivo, representacional, que são os sentimentos e a paixão" (Dér, 2004, p. 61). Deve-se, no entanto, relembrar que a complexificação das formas de manifestação afetivas - que alguns autores caracterizam como cognitivização do processo de desenvolvimento afetivo - só pode ser atingida através da mediação cultural, a partir, portanto, de um ambiente social (Dantas, 1992).

Desta forma, emoção e cognição coexistem no indivíduo em todos os momentos, embora, nas diversas etapas do desenvolvimento, Wallon defende que há um predomínio alternado entre as duas funções. Como lembra Almeida (1999), "a inteligência não se desenvolve sem afetividade, e viceversa, pois ambas compõem uma unidade de contrários" (p.29).

Vygotsky (1993, 1998), por sua vez, de maneira semelhante, assume uma posição segundo a qual o indivíduo nasce como ser biológico, fruto da história filogenética da espécie, mas que, através da inserção na 
cultura, constituir-se-á como um ser sóciohistórico. Ou seja, o ser humano nasce com as chamadas funções elementares, de natureza biológica. Cabe à teoria psicológica explicar como tais funções, a partir da inserção cultural, vão se constituir nas chamadas funções superiores, que caracterizam o ser humano.

Oliveira (1993) resume as ideias basilares da teoria vygotskyana: a) as funções psicológicas superiores têm suporte biológico, pois são produtos da atividade cerebral; o cérebro, assumido como a base biológica do funcionamento psicológico, é entendido como um sistema aberto e de grande plasticidade, o que permite as imensas possibilidades de realização humana e a enorme capacidade de adaptação do homem; b) o funcionamento psicológico fundamenta-se nas relações sociais concretas entre o indivíduo e o mundo exterior, as quais se desenvolvem num processo histórico; assim, as funções superiores constituem-se na/pela cultura; c) a relação homem-mundo é sempre mediada por sistemas simbólicos, o que coloca o conceito de mediação como central na teoria. Dentre os sistemas simbólicos, a fala é considerada fundamental para a construção das funções superiores, sendo internalizada nos anos iniciais do processo de desenvolvimento, passando a funcionar como um instrumento do pensamento.

O desenvolvimento humano pode ser entendido como um processo de apropriação dos elementos e processos culturais, ocorrendo no sentido do externo (relações interpessoais) para o interno (relações intrapessoais), mediado pela ação do outro (pessoas físicas ou agentes culturais). A aprendizagem desempenha, portanto, um papel crucial na medida em que possibilita o processo de desenvolvimento.

É inegável o impacto dessas concepções no pensamento pedagógico. De um lado, aponta que o processo de mediação pedagógica é fundamental na relação que se estabelece entre o sujeito/aluno e o objeto de conhecimento/conteúdos escolares, lembrando que, em sala de aula, o professor é o principal agente mediador, embora não o único. De outro lado, sugere que a mediação pedagógica ocorre através de práticas e situações concretas, o que significa que as mesmas podem ser planejadas de forma a aumentar as chances da aprendizagem com sucesso pelo aluno. Este, por sua vez, é entendido por Vygotsky (1998) como um sujeito interativo, ou seja, um sujeito que desempenha um papel ativo nos processos de interação vivenciados.

Com relação à afetividade, Vygotsky (1993) denuncia a divisão histórica entre os afetos e a cognição, apontando-a como um dos grandes problemas da Psicologia na sua época, ao mesmo tempo em que critica as abordagens orgânicas. Para o autor, as emoções deslocamse do plano individual, inicialmente biológico, para um plano de função superior e simbólico, de significações e sentidos, constituídos na/pela cultura. Nesse processo, internalizam-se os significados e sentidos, atribuídos pela cultura e pelo indivíduo aos objetos e funções culturais, a partir das experiências vivenciadas, sendo crucial o papel do outro, como agente mediador entre o sujeito e os objetos culturais. Assim, para o autor, "as emoções isolam-se cada vez mais do reino dos instintos e se deslocam para um plano totalmente novo." (Vygotsky, 1998, p. 94)

Comparando-se as posições de Wallon e Vygotsky sobre a afetividade, percebe-se que os autores apresentam pontos comuns com relação aos aspectos essenciais do fenômeno em pauta: a) ambos assumem uma concepção desenvolvimentista sobre as manifestações emocionais: inicialmente orgânicas, vão ganhando complexidade na medida em que o indivíduo desenvolve-se na cultura, passando a atuar no universo simbólico, ampliando-se e complexificando-se suas formas de manifestação; b) assumem, pois, o caráter social da afetividade; c) assumem que a relação entre a afetividade e inteligência é fundante para o processo do desenvolvimento humano.

$\mathrm{Na}$ sequência, apresentamos uma síntese das ideias que embasaram todo o trabalho de pesquisa desenvolvido pelos membros do Grupo do Afeto:

a) a produção do conhecimento é um processo que ocorre a partir da relação que se estabelece entre o sujeito e o objeto. Nessa relação, o sujeito tem uma participação essencialmente ativa, ou seja, as relações com os diversos objetos possibilitam ao sujeito a elaboração de ideias, hipóteses, relações, análises, sínteses, etc. Tais processos, na escola, correspondem às relações que se estabelecem entre $\mathrm{o}$ aluno e os diversos conteúdos abordados;

b) toda relação sujeito-objeto é sempre mediada por agentes culturais, que podem ser pessoas físicas ou produtos culturais, como no caso de um texto produzido por alguém, que 
possibilita o contato entre o sujeito e um determinado objeto/assunto. Além disso, podese assumir que a maneira como o processo de mediação ocorrerá é um dos principais determinantes da qualidade da relação que vai se estabelecer entre o sujeito e o respectivo objeto. Na escola, o principal agente mediador entre o sujeito (aluno) e o objeto (conteúdo escolar) é, sem dúvida, o professor, na medida em que todas as práticas pedagógicas dependem de seu planejamento e da forma concreta como são desenvolvidas;

c) as relações que se estabelecem entre sujeito-objeto-mediador também são marcadamente afetivas. Ou seja, tais relações não envolvem somente as esferas cognitivas/intelectuais, mas, simultaneamente, provocam repercussões internas e subjetivas nos sujeitos, de natureza basicamente afetiva;

d) finalmente, como consequência inevitável dos pressupostos acima expostos, assume-se que a qualidade da mediação desenvolvida é um dos principais determinantes da relação que vai se estabelecer entre o sujeito e o objeto de conhecimento, envolvendo, simultaneamente, as dimensões cognitiva e afetiva. Em outras palavras, o tipo de relação afetiva que vai se estabelecer entre o aluno e um determinado conteúdo escolar - relação que pode variar entre fortes movimentos de aproximação ou de afastamento, ou seja, relações de amor ou de ódio, nos seus extremos - vai depender, em grande medida, da concretude das práticas de mediação pedagógica planejadas e desenvolvidas em sala de aula, pelos agentes mediadores, o que nos leva a ratificar que as práticas de mediação pedagógica também são marcadamente afetivas.

O conjunto de dados que temos reunido, através dos projetos desenvolvidos no Grupo do Afeto, permite-nos supor que, quando a mediação pedagógica possibilita ao aluno apropriar-se com sucesso do objeto - o que chamamos de aprendizagem com sucesso, a qual é percebida pelo aluno - aumentam as possibilidades de se estabelecer um vínculo afetivo positivo - de aproximação - entre o aluno e o objeto/conteúdo desenvolvido. Portanto, a aproximação positiva entre o aluno e os conteúdos estudados depende, em grande parte, da consciência que o mesmo desenvolve sobre o sucesso do seu processo de aprendizagem.
Deve-se ressaltar que, nesse processo, o oposto também pode ser verdadeiro - aliás, um processo muito conhecido e intensamente estudado, identificado na literatura como o fenômeno do fracasso escolar. Tal conceito é frequentemente analisado em termos dos índices de repetência e evasão escolares. Entretanto, do ponto de vista afetivo, corresponde a processos de mediação pedagógica, cujo produto final geralmente é marcado por uma relação afetiva negativa - de afastamento - entre o sujeito e o objeto em foco.

Neste sentido, uma das tarefas da pesquisa é descrever e analisar as práticas pedagógicas desenvolvidas em sala de aula (incluindo os processos de mediação que ocorrem fora desse ambiente físico específico) que favorecem, principalmente, o estabelecimento de relações de aproximação entre o sujeito/aluno e o objeto/conteúdos escolares. Isto porque $\mathrm{o}$ conceito de mediação pedagógica não se refere a ideias metafóricas, mas a relações concretamente estabelecidas e vivenciadas, em sala de aula, que podem ser acessadas pelo olhar do pesquisador, através, obviamente, de metodologias adequadas às características dos fenômenos estudados.

Da mesma forma, entendemos também ser tarefa da pesquisa identificar as relações pedagógicas que produzem as situações de afastamento entre sujeito-objeto, caracterizadas por impactos afetivamente negativos nos alunos.

\section{Afetividade nas decisões pedagógicas}

O conjunto dos dados produzidos pelas pesquisas desenvolvidas no Grupo do Afeto (Leite \& Tassoni, 2002, 2007; Leite \& Tagliaferro, 2005; Leite, 2006; Leite \& Falcin, 2006; Leite \& Kager, 2009) nos permitiu identificar algumas das decisões assumidas por um professor, ao planejar e desenvolver o seu curso, seja no ensino fundamental, médio ou superior. Não estamos nos referindo à determinada metodologia de ensino, mas reconhecemos que, independente da orientação teórica assumida pelo docente, em toda situação de ensino planejada, o professor deve assumir algumas decisões que, no seu desenvolvimento prático, terão inevitáveis consequências afetivas na relação que se estabelecerá entre o aluno e os conteúdos 
específicos de ensino, como já abordamos no item anterior.

É possível identificar algumas dessas decisões e seus possíveis impactos. Evitando uma posição reducionista, ao reconhecer que, certamente, há outros fatores que compõem o processo de mediação pedagógica, pretendemos analisar cinco reconhecidas decisões, identificadas, como já explicado, a partir dos dados acumulados pelas pesquisas do Grupo do Afeto. São elas: a) a escolha dos objetivos de ensino; b) a decisão sobre o início do processo de ensino; c) a organização dos conteúdos de ensino; d) a escolha dos procedimentos e atividades de ensino; e) a escolha dos procedimentos de avaliação do ensino.

Segue-se uma síntese de cada uma dessas decisões apontadas:

\section{a) A escolha dos objetivos de ensino}

A escolha dos objetivos de ensino é uma decisão que sempre reflete valores, crenças e concepções por parte de quem os escolhe ou seleciona, seja um grupo de educadores, sejam uma instância de um órgão público, seja um professor isoladamente.

A dimensão afetiva relacionada aos objetivos de ensino refere-se à relevância dos mesmos, reconhecida por uma determinada população ou por um sujeito. O problema se coloca quando o aluno não identifica a relevância dos objetivos propostos, seja para sua vida, seja para a sociedade em que vive, seja para o seu futuro profissional. Neste sentido, grande parte dos objetivos de ensino da escola tradicional tem sido apontada como irrelevante, do ponto de vista do aluno, o que, certamente, colabora com a construção de uma escola divorciada da realidade. Isto não significa que o ensino deve ser basicamente pragmático, mas pode-se assumir que o conhecimento atualmente acumulado nas diversas áreas pode possibilitar aos indivíduos melhores condições para o exercício da cidadania e inserção social numa perspectiva crítica e transformadora. É importante, pois, que a escola selecione objetivos e conteúdos nesta perspectiva e que os alunos reconheçam a relevância dos mesmos, propostos em cada disciplina ou área curricular; isto aumenta as possibilidades de que se estabeleçam vínculos afetivos positivos entre os alunos e os objetivos abordados.
Entretanto, deve-se relembrar que a relação inversa também pode ser verdadeira: um ensino burocrático, com objetivos cuja relevância não é compreendida pelos alunos, pode colaborar para o movimento de afastamento na relação que vai se estabelecer entre o sujeito e o objeto. Obviamente, isso se relaciona com o projeto pedagógico da escola, incluindo os objetivos específicos de cada área curricular; tal projeto ser fruto da reflexão coletiva do corpo docente da escola, processo em que a relevância dos objetivos e conteúdos de ensino deve ser objeto de contínua discussão e avaliação.

\section{b) A decisão sobre o início do processo de ensino}

Os dados das pesquisas realizadas pelo Grupo do Afeto, disponíveis sobre este tema, sugerem que iniciar o ensino a partir do que o aluno já sabe sobre os conteúdos envolvidos aumenta as possibilidades de sucesso do processo de aprendizagem do próprio aluno. Como vimos, tal sucesso tem inegáveis implicações afetivas envolvidas.

A relação inversa também pode ocorrer, sendo frequentemente observada nas escolas: quando o professor decide iniciar seu programa de ensino muito além do conhecimento atual do aluno, cria uma situação em que aumentam as chances do insucesso ocorrer logo no início do processo de ensino-aprendizagem; deterioramse, assim, prematuramente, as possibilidades de se estabelecer uma relação afetivamente positiva entre o aluno e os conteúdos.

Este problema da ausência de conhecimento prévio, necessário para que o aluno inicie a aprendizagem a partir do ponto definido pelo professor, tem sido tradicionalmente apontado por outros autores. Como exemplo, Ausubel (1968) já defendia que dentre os fatores que influenciam a aprendizagem, um dos mais relevantes relaciona-se ao conhecimento prévio do aluno.

A principal implicação pedagógica desta decisão sugere que o início do ensino deve ser definido somente após o professor realizar uma breve avaliação diagnóstica sobre os conteúdos julgados como essenciais, para que o aluno tenha as condições para iniciar o ensino a partir de um ponto determinado. Com isso, diminuem-se as chances de um fracasso prematuro do aluno $-\mathrm{e}$ as consequentes 
relações afetivas negativas na relação que se estabelece com o objeto.

\section{c) A organização dos conteúdos de ensino}

Quando os conteúdos de um curso são organizados de forma aleatória, não se respeitando a lógica da organização do conhecimento da área, dificulta-se o processo de apropriação dos referidos conteúdos pelo aluno. É o caso das situações em que o professor não analisa adequadamente os objetivos de ensino e não identifica os conteúdos envolvidos, bem como a maneira como, por exemplo, os conceitos e princípios de uma determinada área se relacionam. Alguns dados das pesquisas realizadas sugerem que a ausência de uma organização lógica dos conteúdos de um determinado curso pode aumentar as possibilidades de fracasso do aluno, colaborando com a prevista deterioração das relações afetivas entre o aluno e o objeto em pauta. Organizar os conteúdos de forma adequada, portanto, parece estar relacionado com o fato de o professor respeitar a organização epistemológica da respectiva área de ensino; ou seja, como o professor não ensina todo o conteúdo de uma só vez e como o aluno também não aprende dessa forma, é necessário organizar esse conteúdo, sequenciando-o e delimitando-o em cada etapa do ensino. É possível que as dificuldades de análise dos objetivos - geralmente por desconhecimento dos professores - expliquem parcialmente o frequente uso do livro didático como instrumento principal de ensino dos cursos. No entanto, outros fatores também podem estar relacionados com esse fato.

\section{d) A escolha dos procedimentos e atividades de ensino}

A escolha das atividades de ensino está ligada às relações que, efetivamente, vão ocorrer na sala de aula - se o professor vai ministrar aula expositiva e como, se vai dar trabalho em grupo, propor leitura de texto, realizar pesquisa de campo, etc. São, pois, as relações observáveis, geralmente com efeitos imediatos identificados na própria situação, que devem ser adequadas aos objetivos propostos. Neste sentido, é inegável a implicação da dimensão afetiva em cada atividade planejada e desenvolvida. Atividades bem escolhidas e adequadamente desenvolvidas, sem dúvida, aumentam as chances do aprendizado com sucesso por parte do aluno e a consequente relação afetiva de aproximação entre o aluno e os conteúdos envolvidos.

Por outro lado, a escolha dos procedimentos e atividades de ensino apresenta inúmeros desafios que podem transformar tais escolhas em verdadeiras condições de fracasso para o aluno: é o caso, por exemplo, da escolha inadequada de uma atividade, tendo em vista o objetivo proposto. É comum a ocorrência de atividades de ensino não relacionadas com os objetivos específicos esperados; tal fato é reforçado quando as atividades de avaliação utilizadas são radicalmente diferentes das atividades de ensino utilizadas pelo professor. $\mathrm{Ou}$, ainda, o desenvolvimento de uma atividade totalmente desmotivadora, mesmo quando se apresentam objetivos relevantes. Geralmente, os jovens demonstram grande sensibilidade para identificar uma atividade de ensino como adequada ou não, em função dos objetivos propostos.

Além desses problemas, uma atividade de ensino pode ser inadequada por algum problema na sua organização interna: pode ocorrer a ausência de instruções claras, ou ocorrência de intervenções inadequadas por parte do professor, falta de correção com relação ao desempenho do aluno, ou mesmo ausência de atividade relevante prevista para o aluno realizar. Quando tais problemas são frequentes ou adquirem uma grande proporção, a atividade escolar pode se tornar uma prática extremamente indesejável e desmotivadora para o aluno, produzindo, geralmente, efeitos desastrosos e, obviamente, deteriorando, às vezes por completo, as possíveis relações afetivas entre o aluno e os conteúdos abordados. Além disto, são frequentes os casos de afastamento afetivo que podem ocorrer entre $o$ aluno e todo o ambiente escolar.

Finalmente, deve-se destacar que nas atividades de ensino concentra-se, concretamente, grande parte da carga afetiva da sala de aula, através das relações interpessoais entre professores e alunos: olhares, posturas, conteúdos verbais, contatos, proximidade, tom de voz, formas de acolhimento, instruções, correções, etc. constituem aspectos da trama de relações interpessoais que implicam em um enorme poder de impacto afetivo no aluno, positivo ou negativo, dependendo da forma como essas interações são vivenciadas. Daí a relevância dessas decisões: afinal, elas se referem às formas concretas como as relações 
face a face são vividas e percebidas em sala de aula.

\section{e) A escolha dos procedimentos de avaliação do ensino}

Uma das unanimidades observadas nos dados acumulados pelas nossas pesquisas é que a avaliação tradicional tem sido apontada como um dos principais fatores responsáveis pelo fracasso do processo de ensino e aprendizagem, ou seja, pelo distanciamento afetivo entre o sujeito/aluno e o objeto/conteúdo. A avaliação parece tornar-se desastrosa quando seus resultados são utilizados contra o aluno e, obviamente, quando tal relação é identificada pelo aluno. Esta é a lógica do processo de avaliação tradicional, que tem como objetivo, basicamente, o ranqueamento dos alunos, identificando os melhores e os piores. Como todo seu fundamento está centrado na concepção de homem derivada da ideologia liberal, base do sistema capitalista, pressupõese que as diferenças nas capacidades humanas são inatas, distribuídas gaucianamente ${ }^{7}$ entre os homens.

Nesta perspectiva, ensino e aprendizagem são entendidos como processos independentes: ensino é tarefa do professor, aprendizagem é obrigação do aluno - e se esta não ocorre adequadamente, certamente é por algum fator relacionado intrinsecamente com o aluno. Leite \& Kager (2009) apontam os efeitos devastadores que o processo de avaliação tradicional pode produzir nas relações entre sujeito-objeto.

Por outro lado, qualquer alternativa que se coloque implica em profundas mudanças nas concepções de ensino e aprendizagem mudanças inclusive de natureza ideológica, envolvendo visão de homem, de mundo, de sociedade, de relações interpessoais, e, obviamente, de ensino e aprendizagem.

Luckesi (1984) propõe o conceito de avaliação diagnóstica, reconhecendo que, numa sociedade democrática, os resultados do processo de avaliação devem sempre ser utilizados a favor do processo de aprendizagem do aluno, na medida em que altera a lógica de todo o processo tradicional: se a aprendizagem não ocorre adequadamente, o que pode ser detectado pela avaliação, então, deve-se rever as condições de ensino, resgatando-se, assim, a

\footnotetext{
${ }^{7}$ De acordo com a curva de distribuição estatística de Gauss.
}

relação dialética existente entre esses dois processos - ensino e aprendizagem são processos interdependentes. Desta forma, somente quando os dados da avaliação são utilizados a favor do aluno, garante-se uma das principais condições para que se estabeleça uma relação afetivamente positiva entre $o$ sujeito e o objeto. Isto só ocorre, portanto, quando os resultados da avaliação são utilizados, por exemplo, para a revisão das condições de ensino ou subsidiem estratégias que possibilitem que os alunos apropriem-se adequadamente dos conteúdos desenvolvidos.

Deve-se destacar que tais alternativas também implicam no trabalho coletivo desenvolvido pelos docentes na instituição, ou seja, a política de avaliação de ensino não pode ser um tema puramente individual, a ser decidida pelo docente isoladamente, mas exige diretrizes comuns, discutidas e assumidas por toda a instituição.

\section{Uma palavra final}

A partir do exposto, é possível defender que a afetividade está presente em todas as decisões assumidas pelo professor em sala de aula, produzindo continuamente impactos positivos ou negativos na subjetividade dos alunos. Trata-se, pois, de um fator fundante nas relações que se estabelecem entre os alunos e os conteúdos escolares. A qualidade da mediação pedagógica, portanto, é um dos principais determinantes da qualidade dos vínculos que se estabelecerão entre os sujeitos/alunos e os objetos/conteúdos escolares.

Com isto, não estamos defendendo uma proposta pedagógica específica, mas assumimos que não é mais possível que se planejem as condições de ensino sem que se considerem os possíveis impactos afetivos que, inevitavelmente, essas condições produzem nos alunos. Numa perspectiva educacional, isto aponta para um ambiente escolar absolutamente comprometido com o sucesso do processo de aprendizado do aluno, o que só poderá se concretizar através de um projeto pedagógico assumido e desenvolvido pelo coletivo dos professores, com esse compromisso previamente assumido: a aprendizagem do aluno.

É possível, a partir dessas ideias, visualizar a construção de uma escola efetivamente democrática, que possibilite aos alunos 
apropriarem-se com sucesso do conhecimento considerado essencial para o pleno exercício da cidadania.

\section{Referências}

Almeida, A. R. S. (1997). A emoção e o professor: um estudo à luz da teoria de Henri Wallon. Psicologia: teoria e pesquisa, 13(2), 239-249.

Almeida, A. R. S. (1999). A emoção na sala de aula. Campinas: Papirus.

Amado, J., Freire, I., Carvalho, E., \& André, M. J. (2009) O lugar da afectividade na relação pedagógica - contributos para a formação de professores. Revista Sísifo, 8, $75-86$.

Arantes, V. A., \& Aquino, J. G. (Orgs.). (2003). Afetividade na Escola. Alternativas teóricas $e$ práticas. São Paulo: Summus Editorial Ltda.

Ausubel, D. P. (1968). Educational Psychology, a congnitive view. Nova York: Holt, Renehart \& Winston.

Bogdan, R., \& Biklen, S. (1994). Investigação Qualitativa em Educação. Porto: Porto Editora Ltda.

Bosch, P. van den (1998). A Filosofia e a Felicidade. São Paulo: Martins Fontes.

Chauí, M. (2005). Espinosa - uma filosofia da liberdade. São Paulo: Editora Moderna Ltda.

Damásio, A. (2001). O erro de Descartes: emoção, razão e cérebro humano. São Paulo: Cia. das Letras.

Damásio, A. (2003). Em busca de Espinosa: prazer e dor na ciência dos sentimentos. São Paulo: Cia. das Letras.

Dantas, H. (1992). Afetividade e a construção do sujeito na psicogenética de Wallon. In Y. La Taille, H. Dantas, \& M. K. Oliveira (Orgs.), Piaget, Vygotsky e Wallon: teorias psicogenéticas em discussão (pp. 85-98). São Paulo: Summus Editorial Ltda.

Dér, L. C. S. (2004). A constituição da pessoa: a dimensão afetiva. In A. A. Mahoney, \& L. Almeida (Orgs.), A constituição da pessoa na proposta de Henri Wallon (pp. 61-75). São Paulo: Edições Loyola.
Engelman, A. (1978). Os Estados Subjetivos: uma tentativa de classificação de seus relatos verbais. São Paulo: Ática.

Falcin, D. C. (2003). Afetividade e condições de ensino: a mediação docente e suas implicações na relação sujeito-objeto. Trabalho de Conclusão de Curso, Faculdade de Educação, Unicamp, Campinas.

Figueiredo, L. C. (1992). A Invenção do Psicológico: quatro séculos de subjetividade. 1500-1900. São Paulo: EDUC / Escuta.

Franco, A. F. (2009). O mito da autoestima na aprendizagem escolar. Psicologia Escolar e Educacional, 13(2), 325-332.

Giles, T. R. (1993). Dicionários de Filosofia. São Paulo: EPU.

Goyos, A. C. N. (1986). A profissionalização de deficientes mentais: estudo de verbalização acerca dessa questão. Tese de Doutorado, Instituto de Psicologia, USP, São Paulo.

Grotta, E. C. B. (2000). Processo de formação do leitor: relato e análise de quatro histórias de vida. Dissertação de Mestrado, Faculdade de Educação, Unicamp, Campinas.

Guanais, M. A. B. (1995). O trabalho e a Qualidade Total: contribuições $d a$ Psicologia Organizacional. Dissertação de Mestrado, Faculdade de Educação, Unicamp, Campinas.

Larocca, P. (1999). Psicologia na Formação Docente. Campinas: Ed. Alínea.

Leite, S. A. da S., \& Tassoni, E. C. M. (2002). A afetividade em sala de aula: as condições de ensino e a mediação do professor. In R. Azzi, \& A. M. Sadalla (Orgs.), Psicologia e Formação Docente (pp. 113-141). São Paulo: Casa do Psicólogo.

Leite, S. A. da S., \& Tagliaferro, A. R. (2005). A afetividade na sala de aula: um professor inesquecível. Psicologia Escolar $e$ Educacional, 9(2), 247-260.

Leite, S. A. da S. (Org.) (2006). Afetividade e Práticas Pedagógicas. São Paulo: Casa do Psicólogo. 
Leite, S. A. da S., \& Colombo, F. A. (2006). A voz do sujeito como fonte primária na pesquisa qualitativa: a autoscopia e as entrevistas recorrentes. In S. G. Pimenta, E. Ghedin, \& M. A. R. S. Franco (Orgs.), Pesquisa em Educação: alternativas investigativas com objetos complexos (pp. 117-136). São Paulo: Edições Loyola.

Leite, S. da S., \& Falcin, D. C. (2006). O professor inesquecível: afetividade nas práticas pedagógicas. In M. T. C. Souza, \& V. S. R. Bussab (Orgs.), Razão e Emoção: diálogos em construção (pp. 213-254). São Paulo: Casa do Psicólogo.

Leite, S. A. da S., \& Tassoni, E. C. M. (2007). Afetividade e Ensino. In E. T. Silva (Org.), Alfabetização no Brasil - questões e provocações da atualidade (pp. 113-137). Campinas: Autores Associados.

Leite, S. A. da S., \& Kager, S. (2009). Efeitos aversivos das práticas de avaliação da aprendizagem escolar. Ensaio - avaliação $e$ políticas públicas em Educação, 17(62), 109-134.

Luckesi, C. C. (1984). Avaliação Educacional Escolar: para além do autoritarismo. Tecnologia Educacional, 61, 6-15.

Ludke, M. \& André, M. E. D. (1986). Pesquisa em Educação: abordagens qualitativas. São Paulo: EPU.

Mahoney, A. A. (1993). Emoção e ação pedagógica na infância: contribuições da psicologia humanista. Temas em Psicologia, 1(3), 67-72.

Mahoney, A. A. (2004). A constituição da pessoa: desenvolvimento e aprendizagem. In A. A. Mahoney, \& L. R. Almeida (Orgs.), A constituição da pessoa na proposta de Henri Wallon (pp. 13-24). São Paulo: Edições Loyola.

Marcondes, D. (2000). Iniciação à História da Filosofia - dos pré-socráticos a Wittgenstein. Rio de Janeiro: Jorge Zaar Editor.

Oliveira, M. K. (1992). O problema da afetividade em Vygotsky. In Y. La Taille, H. Dantas \& M. K. Oliveira (Orgs.), Piaget, Vygotsky e Wallon: teorias psicogenéticas em discussão (pp. 75-84). São Paulo: Summus Editorial Ltda.
Oliveira, M. K. (1993). Vygotsky - aprendizado $e$ desenvolvimento, um processo sóciohistórico. São Paulo: Scipione.

Pinheiro, M. M. (1995). Emoção e afetividade no contexto da sala de aula: concepções de professores e direções para o ensino. Dissertação de Mestrado, PUC, São Paulo.

Ribeiro, M. L., \& Jutras, F. (2006) Representações sociais de professores sobre afetividade. Estudos de Psicologia, 23(1), 39-45.

Ribeiro, M. L. (2010) A afetividade na relação educativa. Estudos de Psicologia, 27(3), 403-412.

Sadalla, A. M. F. A., \& Larocca, P. (2004). Autoscopia: um procedimento de pesquisa e de formação. Educação e Pesquisa, 30(3), 419-433.

Simão, L. M. (1982). Estudo descritivo de relações professor-aluno I: a questão do procedimento de coleta de dados. Psicologia, 8(2), 19-28.

Spinoza. (2009). Ética (T. Tadeu, Trad.). São Paulo: Autêntica.

Tagliaferro, A. R. (2003). Meu professor inesquecível: a construção de uma memória coletiva. Trabalho de Conclusão de Curso, Faculdade de Educação, Unicamp, Campinas.

Tassoni, E. C. M. (2000). Afetividade $e$ Produção Escrita: a mediação do professor em sala de aula. Tese de Doutorado, Faculdade de Educação, Unicamp, Campinas.

Tunes, E. (1981). Identificação da natureza e origem das dificuldades de alunos de pósgraduação para formularem problemas de pesquisa através de seus relatos verbais. Tese de Doutorado, Instituto de Psicologia, USP, São Paulo.

Vasconcelos, M. S. (2004). Afetividade na escola: alternativas teóricas e práticas. Educação e Sociedade, 25(87), 616-620.

Vygotsky, L. S. (1993). Pensamento $e$ Linguagem. São Paulo: Martins Fontes.

Vygotsky, L. S. (1998). O desenvolvimento psicológico na infância. São Paulo: Martins Fontes. 
Wallon, H. (1968). A evolução psicológica da criança. Lisboa: Edições 70.

Wallon, H. (1971). As origens do caráter na criança. São Paulo: Difusão Europeia do Livro.

Wallon, H. (1978). Do acto ao pensamento. Lisboa: Moraes Editores.

Zanelli, J. C. (1992). Formação profissional e atividades de trabalho: a análise das necessidades identificadas por psicólogos organizacionais. Tese de Doutorado, Faculdade de Educação, Unicamp, Campinas.
Recebido em 15 de Maio de 2012 Aceite em 19 de Agosto de 2012 Publicado em 31 de Dezembro de 2012 